\title{
NG2/CSPG4 Proteoglycan as a Novel Prognostic Indicator and Therapeutic Target in Malignant Cancer

\author{
Hongyu Zhang ${ }^{1}$, Ping Bie ${ }^{1}$, Zhang Leida ${ }^{1}$, Zhang $\mathrm{Xia}^{2}$ and Lianhua Bai ${ }^{1 *}$
}

${ }^{1}$ Hepatobiliary Institute, Southwest Hospital, Third Military Medical University, Chongqing, 400038 P.R. China

${ }^{2}$ Institute of Pathology and Southwest Cancer Center, and Key Laboratory of Tumor Immunopathology of Ministry of Education of China, Southwest Hospital, Third Military Medical University, Chongqing, 400038 P.R. China

\begin{abstract}
This review article describes the interaction of Neuron-glia 2 Chondroitin Sulfate Proteoglycan 4 (NG2/CSPG4) in cancer cell matrix, and its role within the cancer cell matrix in promoting angiogenesis and its potential clinical use as a novel immune drug target. Malignant cancer is maintained by a cross-talk between the cancer cells and cancer cell matrix where the activated cancer cell matrix nurtures the advancing cancer cells by providing Extracellular Matrix (ECM), neovasculature and stimulatory growth factors. Researches in recent years have accumulated a wealth of novel insight into mechanisms by which how cancer cells are co-evolved with activated cancer cell matrix throughout cancer settings. Currently, the cancer cell matrix is considered as an important "effector" in carcinogenesis. Once tightly defined cell matrix in normal tissue occasionally becomes sabotaged, the inevitable malignant progression will flip on. NG2/CSPG4 is a big multifunctional transmembrane proteoglycan with limited expression in normal tissues and its unparalleled structural-functional diversity endows it with the ability to serve as critical mediator. We describe here how the manipulation of NG2/CSPG4 on the processes driving malignant cancer cell matrix activation promotes carcinogenesis through the alteration of cancer cell adhesion, infiltration, migration, proliferation and angiogenesis, and how it will be possibile to design a decisive strategy for the development of a novel therapy specifically targeting this macromolecule for malignant cancer treatment.
\end{abstract}

Keywords: NG2/CSPG4; Proteoglycan; Cancer stromal cells; Pericytes; Growth factors

\begin{abstract}
Abbreviation: CNS: the Central Nerve System; CSCs: Cancer Stem Cells; CTCs: Circulating Cancer Cells; ECs: Endothelial cells; ECM: Extracelluar matrix; EMT: Epithelial-Mesenchymal Transition; EPC: Angiogenic Progenitor Cells; FAK: Focal Adhesion Kinase; FGFs: Fibroblast Growth Factor; GBM: Glioblastoma; Heparin Sulfate (HS); High-Molecular-Wight Melanoma-Associated Antigen; HMP: Human Melanoma Proteoglycan; IHC: Immunohistochemical Staining; mAb: HSCs: Hepatic Stellate Cells; IR: Ionising Radiation; MART1: Melanoma Antigen Recognized by $\mathrm{T}$ cells; mAb; Monoclonal Antibody; MM: Malignant Mesothelioma; MSCs: Mesenchymal Stem Cells; NG2/CSPG4: Neuron-glia 2 Chondroitin Sulfate Proteoglycan 4; NSCs: Neural Stem Cell; OPCs: Oligodendrocyte Precursor Cells; PDGF: Platelet-Derived Growth Factor; PCs: Pericytes; HMW-MAA: High Molecular Weight-Melanoma Associated Antigen; RNAi: RNA Interference; SCID: Severe Combined Immune Deficiency; shRNA: Small Hairpin RNA; siRNA: Small Interfering RNA; VEGF: Vascular Endothelial Growth Factor
\end{abstract}

\section{Introduction}

Malignant cancer is a broad group of diseases involving unregulated cell division, uncontrollably growth and invading nearby parts of the body. Despite of distinct etiological and clinical features, most cancers have common mechanisms in biological progress. They arise from normal cells through the alterations of tightly growth controlled genetic system. It is well known that cell matrix contains several components including ECM, collagens, Endothelial Cells (ECs), Pericytes (PCs), fibroblasts and various classes of leukocytes [1]. When cancer occurs, the surrounding cell matrix changes into activated state, followed by creating a dynamic signaling circuitry to promote cancer cell initiation and proliferation, which ultimately results in incurable diseases. Advances in the early diagnosis and surgical removal of primary pathological changes have prevented from cancer growth and reduced mortality rate. However, incurable metastatic migration still remains a big clinical knotty. As restricted distribution in normal tissues and highly related to the cancer cell matrix [2], NG2/CSPG4 has recently received more attention in the cancer research field.

The most important concept regarding the significance and function of NG2/CSPG4 has been evolved from the study of rat orthologs [3]. Since then, many studies trace this unique protein in a broad of fields under both physiological and pathological situations [46]. NG2/CSPG4 was first reported in a malignant cancer of melanoma in 1981 [7] which identified NG2/CSPG4 as a highly glycosylated integral membrane proteoglycan. NG2/CSPG4 consists of two chondroitin sulfate proteoglycan components (N-linked $280 \mathrm{kDa}, 450$ $\mathrm{kDa}$ ) which express on cell membrane [8]. Since both $280 \mathrm{kDa}$ and 450 $\mathrm{kDa}$ comprise of the same core protein but appear to be independently expressed, a challenging would be to ascertain how effectively to what extent to target NG2/CSPG4 in cancer cell matrix action that associates to carcinogenesis [9]. This challenge may be more precise for targeting therapeutics to eventually eliminate progressive malignant cancers and for potential targeting opportunities to develop drugs aimed at the NG2/CSPG4-expressing cancer cell matrix and to delineate emerging areas of researches in malignant cancers.

*Corresponding author: Lianhua Bai, Hepatobiliary Institute, Southwest Hospital, The Third Military Medical University, No. 30 Center Street, GaotanYan, ShapingBa District, Chongqing, 400038 P.R. China, Tel: +86-68765808; Fax: +86-2365462170; E-mail: hongyz83@hotmail.com

Received December 12, 2013; Accepted February 13, 2014; Published February 15,2014

Citation: Zhang H, Bie P, Leida Z, Xia Z, Bai L (2014) NG2/CSPG4 Proteoglycan as a Novel Prognostic Indicator and Therapeutic Target in Malignant Cancer. J Stem Cell Res Ther 4: 171. doi:10.4172/2157-7633.1000171

Copyright: (C) 2014 Zhang $\mathrm{H}$, et al. This is an open-access article distributed under the terms of the Creative Commons Attribution License, which permits unrestricted use, distribution, and reproduction in any medium, provided the original author and source are credited. 


\section{Expression of NG2/CSPG4 in Normal Tissue and Malignant Cancer}

\section{In normal tissue}

Rat NG2/CSPG4 was found to share high-sequence homology with human melanoma cancer in 1981 [3]. This study reported that shares high-sequence homology with High-Molecular-Weight MelanomaAssociated Antigen (HMW-MAA). Eighteen residues at aminoterminus of rat NG2/CSPG4 are identical to those of human melanoma proteoglycan (HMP). Both NG2/CSPG4 and HMP are denoted as NG2/HMP [10]. Later, NG2/CSPG4 homolog has also been identified in mice and termed as AN2 [11], indicating that the evolution of NG2/CSPG4 is somehow conserved. NG2/CSPG4 composes of three functionally distinct subunits and its distribution was originally thought to be restricted only in PCs and melanocytes [12]. Recently it has become apparent that the distribution of NG2/CSPG4 is broad such as in interfollicular epidermis, oral mucosa, out root sheath, hair follicle, chondrocytes, smooth muscle cells, anigomyolipomas, and muscular junction of postnatal skeletal muscle, migroglia and mesangial cells [13-19]. Interestingly, ablation of NG2/CSPG4 has been found to be associated with both deficiency in progenitor cell pools and defective vasculature, suggesting its important role in the development tissue homeostasis, tissue repair and angiogenesis [20].

In the late 1980s, investigators found that NG2/CSPG4 "calms" in progenitor cells but "acts" once the cells make an initial commitment to a particular cellular lineage [21], suggesting that NG2/CSPG4 is not so much a marker for a specific cell type, but is more of a marker for an "activated" (as opposed to quiescent or calm) status of cells. Evidence of Oligodendrocyte Precursor Cells (OPCs) in the diseased Central Nerve System (CNS) suggests that NG2/CSPG4 assumes activated morphology [22] and starts functioning due to any insults or disturbances to the CNS by changing cellular environment to produce beneficial cells [23]. Expression of NG2/CSPG4 in other progenitor cells like Mesenchymal Stem Cells (MSCs), chondroblasts, osteoblasts, immature keratinocytes, muscle progenitors, brain perivascular and microvascular cells $[16,24-27]$ indicates a role of NG2/CSPG4 in cell matrix maintenance. More recently, we showed that NG2/CSPG4 expressed in multiple adult mammal organs like bone marrow, liver, pancreas, lungs, eyes, heart and kidneys, and exhibited stem/progenitor activities [28], suggesting that the origin and function of NG2/CSPG4 are not unique in the CNS but are also found in other organs. Whether NG2/CSPG4-expressing cells are PCs or a reservoir for harboring MSCs [29] is still under investigation.

\section{In malignant cancer}

There is tantalizing evidence that NG2/CSPG4 is highly expressed in malignant cancer [30-33]. Analysis of NG2/CSPG4 in surgical removed cancer lesions showed that NG2/CSPG4 deposited into cell matrix during cancer cell matrix reaction and participated in the organization of cell matrix to modulate cancer cell stimulation and migration as well as metastasis [34]. A set of elegant experiments in Immunohistochemical Staining (IHC) reactions with NG2/ CSPG4 specific Monoclonal Antibodies $(\mathrm{mAb})$ have showed that cancers of NG2/CSPG4-expressing PCs are frequently devoid of ECs [35], suggesting the early role of NG2/CSPG4-expressing PCs in pathological conditions in vessel formation and dysregulation of PCEC interaction. By utilizing well-defined histopathological criteria, a well designed study has been directed at assessing the frequency of NG2/CSPG4 expression in primary and metastatic cancers in different anatomic sites. The expression of NG2/CSPG4 has not been found to vary between primary and metastatic lesions at early stage whereas significantly higher expression in metastatic lesions at later stage $[36,37]$, suggesting that NG2/CSPG4 plays a role in the motile potential of cancer cells that are highly positively correlated with a worse prognosis. Given its multifunctional roles in brain glioblastoma (GBM) biology, researchers have hypothesized that increased proportions of NG2/CSPG4 expression in GBM stem cells may have an impact on patients' survival outcomes [38]. Several studies have provided evidence to link therapy resistance to subpopulation of GBM cells characterized by expression of the neural stem cell (NSC) marker (Nestin) and the cancer stem cell (CSC) marker (CD133/prominin) [39]. The results have demonstrated that highly expression of NG2/CSPG4 on CD133, Nestin- and prominin-expressing CSCs is associated with shorter survival but independent of age, treatment and chemotherapy. In GBM, for example NG2/CSPG4 positive cells with increased PRDX-1 activity, a marker representing for oxidative stress, showed resistance to radiotherapy by the rapid induction of a DNA damage signaling response and this response could be counteracted by NG2/CSPG4 and PRDX-1 knockdown in the NG2/CSPG4 expressing cells but not in control NG2/CSPG4 negative cells [38]. This experiment suggests that NG2/CSPG4, as a prognostic factor for poor survival, promoted GBM Ionising Radiation (IR) resistance and multi-drug chemoresistance.

\section{NG2/CSPG4 Proteoglycan as an Activated Cell Matrix in Cancer Progress}

In historical studies dating back to 1992, the gene expression of CSPG4 in cancer patients suggests that altered distribution of NG2/ CSPG4 may serve as a prognostic factor and an important targeting element in malignant cancers $[5,40,41]$. Based on the fact that NG2/ CSPG4 has been largely studies and examined in the context of malignant pathology, we described and accumulated here a wealth of novel insights into the mechanisms by which cancer cells interact with activated NG2/CSPG4 related cancer cell matrix.

\section{What is the term of cell matrix?}

The most concise answer is: The Material is to fill space between cells called Cell Matrix Or Stromal Tissue. It is well known that the tissues of a multicellular organism contain two main components, the cells themselves and the material that lies between the cells. This material is called cell matrix, dismissed as sole function "Adorn or Package". However, it has now become gradually clear that the cell matrix is much more significant in its function for cancer survival now than before because of its interaction with the surrounding matrix that is one of the major controls of cell behaviors. Besides, it provides a barrier to isolate tissues from each other, offers navigational cues for migratory cells, conveys signals to alter cell behavior, and sequesters biologically active compounds such as growth factors.

In animals, the cell matrix appears in two main forms: (1) a basement membrane underlying the epithelial cells of the tissue which effectively separates the epithelium from underlying connective tissues; (2) connective tissues surrounding the cells of the mesenchymal part of the tissue. The cell matrix is associated with 'connective tissues' and frequently fibrous, particularly in load-bearing tissues such as artery walls, tendons, cartilage and skin [42]. Although the mixtures of the cell matrix vary between organisms, the internal structure is highly organized. Cells embedded in the cell matrix make contact with each other mainly through specialized matrix receptor molecules, which allows the cells to adhere to the matrix to signal the presence of particular matrix components to the internal machinery of the cell and the matrix to control cell behavior. The cell matrix that is mainly composed of 
both proteoglycans and glycoproteins is able to bind to specific sites on those cell matrix proteins and results in the formation of matrix as a highly cross-linked gel. Approximately 100 known components are located in the cell matrix, but not including molecules such as growth factors that are not structurally part of the matrix but which bind to it. However, most of the cell matrix materials are accounted for a few dominant types of moleculed that include: Collagens, Elastin, Fibrillin, Fibronectin, Hydroxyapatite, Laminin, Matrix metalloproteinases (MMPs) and Nidogen. Collagens are the most dominant glycoproteins in the cell matrix while NG2/CSPG4 is one of the big proteoglycans located in the cell matrix, and many can be bound by receptors on cells to promote cell-cell matrix interaction. Most can take up water to form hydrated gels into which collagen fibres are embedded, particularly the Heparin Sulfate (HS) in NG2/CSPG4 proteoglycan, bind to a variety of growth factors to concentrate them in the cell matrix and prevent their diffusion to other parts of the body.

\section{Activated NG2/CSPG4 proteoglycan in cancer cell adhesion (cancer establishment)}

The cell matrix is not a static structure and can be activated when responds to aberrant signals. Once activated, proliferative cancer cells interact with activated cancer cell matrix by using a variety of receptors on their plasma membranes including NG2/CSPG4 proteoglycan. As a result, the cancer cell matrix has emerged as a prime determinant of cancers.

Cancer cell matrix supports cancer cell adhesion and transmits signals through cell-surface adhesion receptors [43-47]. It has been largely reported that the most important stromal ECM receptors in cancer cells belong to integrin family. Localization of NG2/CSPG on cancer cells indicates that this proteoglycan is capable of modulating both cell-ECM and cell-cell interactions. NG2/CSPG4 can also indirectly regulate cell and cell matrix interactions by serving as a co-receptor which communicates with cancer cells by outside-in and inside-out signaling mechanisms during adhesion $[48,49]$. It has been reported that the aberrant signals-induced morphological changes of NG2/CSPG4-positive cells is only within hours but can persist for several weeks [50].

Upregulation of NG2/CSPG4 in cancer lesions leads to cancer cell adhesion, which links NG2/CSPG4 signals to the activation of integrin receptor family [51]. A set of refined experiments by using a4 3 integrin-subunit have demonstrated that NG2/CSPG4 interacts with the a4 $\beta 1$ integrin-subunit modulated-cell adhesion to type VI collagens [52]. Adhesion to the collagens of the cancer cell matrix "wakes up" cancer cells, which allows integrins to form associations with various signal transduction molecules such as Focal Adhesion Kinase (FAK). Activation of FAK can phosphorylate a variety of targets to control cell survival, differentiation and proliferation [53]. Therefore, high expression of NG2/CSPG4 in cancer lesions suggests that NG2/CSPG4 may modulate cancer progression via FAK signaling pathway. Studies over the past several years on some of the signaling pathways involved in normal-to-malignant cell transition suggest that integrin-regulated FAK may be activated by NG2/CSPG4 [53]. Several studies that reduction of cancer cell adhesion and spreading by using monoclonal antibody against the NG2/CSPG4 core protein [49] or enhancement of cancer cell metastasis by using the NG2/CSPG4null cancer cells [33] suggest that NG2/CSPG4 may be a key factor in integrin-controlled cancer cell adhesion $[9,54]$. Other signaling pathways such as Wnt [55,56], Prolantin-jak-2-Stat-5 [56], GTPaseRac-Rho [10], ERK1/2 [9] and PI3K/AKT [54] can also be originated by NG2/CSPG4 but are beyond our discuss scope in this review.

\section{Activated NG2/CSPG4 proteoglycan as a mitogenic receptor in cancer cell proliferation (cancer progression)}

The functions in normal organs are determined by reciprocal communication between the cells in an epithelial layer and their surrounding cell matrix. The same organizational principles apply to most of malignant cancers. The progression from a hyperproliferative state to malignancy can be characterized by an increased abnormal communications between all types of cells comprising the cancer mass [57]. During gain-of-function, NG2/CSPG4 as a cell surface receptor for ECM components changes cancer cell matrix and influences cancer cell adhesion as described above. Once NG2/CSPG4 disrupted, normal communication between different cell types within a cancer would cause cancer cell proliferation leading to cancer progress [58]. This process is thought to be highly dependent upon signaling stimulations by several growth factors. Investigation of the stimulation served by NG2/CSPG4 to link between NG2/CSPG4 activation and its contribution to critical processes of remodeling cancer progress would merit in the future clinic.

Ample studies suggest that NG2/CSPG4 expression is associated with a proliferative cell phenotype and is often found in tissues exhibiting elevated proliferation, such as in development and in a variety of cancers [32]. As known, the cell matrix surrounding cells contains NG2/CSPG4 proteoglycans that provide both structural support and contextual information for cells to determine the correct response to a given set of stimuli [59]. A large number of studies showed that NG2/CSPG4 influences cell proliferation by interacting with growth factors acting as high-affinity receptors [58,60-62]. Heparan sulfate (HS) is well-known for their ability by serve as co-receptors for growth factors due to their affinity for the NG2/CSPG4 proteoglycans where its core protein is responsible for growth factor bindings [63]. Besides, epithelial cells can also initiate incorrect matrix signaling to produce growth factors that, in turn, stimulate in appropriate proliferation of neighboring epithelial cells [64]. Alternatively, an aberrant matrix component produced by matrix cells in response to a local stress can be perceived by neighboring epithelial cells as a signal to proliferate or to enter a new developmental pathway $[59,65,66]$. Below we selected several main contributions of growth factors related to NG2/CSPG4 and discussed their main contributions in carcinogenesis.

Fibroblast Growth Factor (FGF) is a key factor in the regulation of angiogenesis in malignant cancers. Its main contribution is to convert quiescent-stationary vascular cells to mitotic phenotypes. It has been revealed that perturbation of responsiveness could be confirmed in NG2/CSPG4-deficient PCs or in the cells isolated from NG2/CSPG4 null mice to paracrine and autocrine stimulation through FGF, while proliferation induced by other growth factors was equivalent in wild-type cells [67]. By 5-bromo-2- Bromodeoxyuridine (BrdU) incorporation tested in an ischemic retinal and corneal vascularization models induced by FGF2, blood vessel development is decreased more than 2-fold with genetic ablation of NG2/CSPG4 [68] and the most obvious caused this change is the reduced proliferation of PCs in the absence of NG2/CSPG4. This study suggests that NG2/ CSPG4-expressing PCs may promote cancer vascularization and mediates expansion of the transformed cell population [69]. It may also be possible that the reduced proliferation could contribute to the reduction in numbers of NG2/CSPG4-expressing PCs.

It has been considered that NG2/CSPG4 rearranges activated PCs in malignant cancers by probably receiving Platelet-Derived Growth Factor (PDGF) signaling [70]. PDGF as a mitogen is another contributor to the expansion of the cell matrix in cancer progression because of 
NG2/CSPG4 binding potential of collagen types to PDGF [71,72]. During cancer progression, regulation of NG2/CSPG4-expressing PC' responds to PDGF and the need of NG2/CSPG4-expressing PCs to receive PDGF signal correlates positively to cancer cell proliferation [73]. In other works, the cancer cell-expressing NG2/CSPG4 generates a supportive "niche" by producing matrix-modulating growth factors. NG2/CSPG4 has also been proposed to be a critical adapter protein in the growth factor-mediated perivascular activation. This process has led to the identification of a growth factor-binding site within the central portion of the core protein located in NG2/CSPG4 [74]. Knockout mice study suggests that presence of NG2/CSPG4 results in the cancer PC proliferation via PDGF signaling-involved paracrine mechanism [75]. Based on PCs co-expressing NG2/CSPG4 and PDGF receptor $\beta$ (PDGFR- $\beta$ ) [71,76], PDGF signaling of cancer-associated PCs with NG2/CSPG4 expression would play a critical role in angiogenesis such as vessel abnormal morphology, increased endothelial proliferation and poorly perfused tortuous vessel formation [77]. Immunohistochemitray assay of Ki67 (MIB-1), a proliferation-associated nuclear protein that expresses during G1 to M phases in the cell cycle, has demonstrated that NG2/CSPG4-expressing PCs in cancers proliferate much more than their NG2/CSPG4 negative counterparts $[78,79]$. Similar results have also been found in melanoma cancer cells [80]. Furthermore, studies using animal model indicate that the presence of PDGFR- $\beta$ and NG2/CSPG4 in PCs could protect ECs against inhibition of Vascular Endothelial Growth Factor (VEGF) signaling. Simultaneous inhibition of PDGFR- $\beta$ on PCs therefore improves the effect of VEGF inhibitors on ECs. Such bivalent relationship may emphasize in a wealth of studies to confirm the pivotal role of PDGF-BB/PDGFR- $\beta$ for anti-angiogenic therapy. Studies involved in the cross-talk between PDGFR- $\beta /$ NG2/ CSPG4-expressing PCs and ECs in cancer progression suggest that regulation of angiogenesis in cross talk between PCs and ECs is critical for cancer cell matrix activation. During vessel formation, ECs produce PDGFR- $\beta$ ligand (PDGF-BB) which promotes recruitment of activated PCs to migrate into microvasculature and to enhance EC differentiation. Recruitment of PCs by ECs is known to be essential for maintenance of cancer angiogenesis. Abnormal blood vessels in cancer angiogenesis are leaky and tortuous vessels that are often poorly perfused. Thus, anti-angiogenic therapy targeting NG2/CSPG4FGFR/ PDGFR- $\beta$-expressing PCs will be a promising approach for enhancing anti-angiogenic therapy in malignant cancers.

Together, it is believed that NG2/CSPG4 proteoglycan possibly acts as ligand receptor. High-affinity interactions between growth factor and receptor induce conformational changes of NG2/CSPG4. Another study indicates that HS chains contain a specific carbohydrate sequence ( $\mathrm{N}$-sulfate and iduronate-2-sulfates) which is an essential binding site for FGF [81], but not for the proteoglycan component of the transforming growth factor beta (TGF- $\beta$ ) [82], suggessting that different binding sites allow for the binding of more than one growth factor to the same NG2/CSPG4 proteoglycans [83]. Therefore, removal of NG2/CSPG4 results in a dramatical reduction of the binding of growth factor to the cancer cells and leaves the mitogenic activity of growth factors to cancer cells unaffected.

\section{Activated NG2/CSPG4 Proteoglycan in Cancer Angiogenesis}

Angiogenesis is required for malignant cancer cell survive. To meet the metabolic needs of a rapidly growing cancer mass, development of a new blood vasculature is essential. A large growing body of data suggest that over-expression of NG2/CSPG4 on angiogenesis is associated with the formation and poorly prognosis of aggressive cancers $[84,85]$.
Below section we illustrate the central role of NG2/CSPG4 that is associated with angiogenesis in different malignant cancers.

\section{What is angiogenesis?}

The process for accomplishment of the formation of new vesslse generated on the preexisting vascular beds called angiogenesis. The term of angiogenesis was first used in 1787 by John Hunter, a British surgeon who described the formation of new vessels de novo. There were very few reports of cancer angiogenesis until almost 100 years later and these were mainly anatomical studies. In 1971, Judah Folkman was first proposed the essential role of angiogenesis in cancer growth and described cancers as "hot and bloody) [86]. The expanding vasculature provides nutrients to cancer tissues and routes for cells to leave or enter the circulation. Remolded blood vessels in most pathological conditions differ from normal vessels at multiple levels.

During angiogenesis under normal physiologic condition, two well-orchestrated processes occur: the changes in morphogenesis that requires EC proliferation and the reconstitution of the cell matrix components [87]. Although novel vessel formation under physiologic or pathological conditions is different, the molecules and mechanisms implicated are common. Once ECs display a proliferative phenotype, recruitment of perivascular supporting cells such as PCs enables stabilization of nascent vessels, functional lumen formation and appropriate blood flow. Both ECs and PCs regulate blood vessel formation, maturation and specification. ECs form the interlining of the vessel wall and PCs wrap around blood vessels. Communication between these two distinct vascular cell types occurs by direct cell contact and paracrine signaling pathways. Loss of PCs can form hyperdilated and hemorrhagic blood vessels that lead to conditions of diseases like edema, diabetic retinopathy and even embryonic lethality. In cancer blood vessels, co-express PDGFR- $\beta$ and NG2/ CSPG4, PC divisive deficiency is observed when PDGF-BB/PDGFR- $\beta$ signaling is deleted in the ECs $[88,89]$, suggesting the lack of PCs due to disruption in PDGFR- $\beta$ signaling on ECs are unable to expand and spread along the newly formed vessels because of their reduced migratory and proliferative capabilities [86]. PC dysfunctions can also resulte in increased EC apoptosis and metastatic spread, suggesting that PCs in malignant cancers are implicated in vessel maintenance, EC survival and potentially cancer dormancy. Specific mutations in the PDGFR- $\beta$ gene in mice lead to disruption of distinct and different signaling pathways, which reveals that PDGFR- $\beta$-dependent signaling circuits are rather additive than specific for PC recruitment [90]. Based on their functional importance, PCs present a complimentary target to ECs in malignant cancers. Therefore, combinatorial targeting of both cell types might have the potential to more efficiently diminish cancer vessels that halt subsequent cancer progress.

Despite extensive angiogenesis in malignant cancers, blood flow is inadequate to support cancer cells viability. Additional activation of proangiogenic molecules in malignant cancers is required and this procedure is regulated by positive and negative acting mediators to keep balanced equilibrium tightly in check under homeostatic conditions. To date, the link among expansion, invasion, proliferation and metastasis of cancers adequate vascular supply has been well established, as Algire et al. summed up in 1945 "rapid cancer growth is dependent on the development of a rich vascular supply." This was brought forward by Folkman in 1971. All suggest that the growth of malignant cancers depend on the process of angiogenesis, thus, manipulating the stability of the malignant cancer vasculature may constitute a viable anticancer therapeutic strategy. 


\section{NG2/CSPG4 involves angiogenesis in several malignant cancers}

Aberrant expression of NG2/CSPG4 proteoglycan in angiogenic vasculature is associated with an aggressive disease course in several malignancies [39,78]. For example, PCs in malignant cancers differ from the one in normal tissues. They appear to be more loosely attached to the vasculature and their cytoplasmic processes can extend into the cancer mass suggesting PCs are involved in neogrowing vasculature in malignant cancers. The role of NG2/CSPG4 in promoting PC neovascularization is evident during cancer proliferation. The best evidence for the importance of PCs in vascularization is the impaired PC development by genetic ablation of PDGFR- $\beta$ that resultes in the production of aberrant vasculature [91]. A study evidenced that compared to blood vessels in wild type cancer, vessels in NG2/CSPG4 null cancers exhibit reduced diameters and diminished investment by PCs. Another study indicated that mammary cancers in MMTVPyMT (mouse mammary tumor virus) transgenic mice developed more slowly and reduced metastasis [92]. A recent study confirmed a functional significance of PDGFR- $\beta$ signaling in NG2/CSPG4expressing PCs for cancer angiogenesis. With PDGF retention mice (PDGF-Bret/ret) disrupted PDGF chemotactic gradient in vivo that mediates PDGF binding to NG2/CSPG4 proteoglycans in cancer cell matrix, while implanted cancers into the PDGF-Bret/ret mice showed hemorrhagic and contained few PCs around the cancer blood vessels which were hyperdilated. Ectopic expression of PDGF in those cancer cells was able to increase PC density but failed to cause PCs to attach more firmly to blood vessels. These results indicate that localized PDGF from the endothelium is essential for proper PC adhesion to the vessel wall [93]. Since PCs in most of malignant cancers used mechanisms for angiogenesis such as regulating vessel integrity, maintenance and function that are similar to the PCs used in developmental angiogenesis, therefore, it will be interesting to see whether ablation of NG2/CSPG4-expressing PCs on endothelial would disturb the cellmediate EC recruitment.

Melanoma: The incidence of melanoma has risen faster in the last 30 years and this increase is mostly considered to be linked to increased angiogenesis. Growth of new capillary blood vessels $[94,95]$ to increase in blood flow [96] supplies melanoma cancer with oxygen and nutrients for its proliferation, metastases and progress [97]. Melanomas can develop anywhere on the body but they are most frequently discovered in skin areas with greatest sun exposure. Because of poor survival rates and metastasizes very early, the prognosis in melanoma process is significantly worse it is a reflection of the two main challenges in this cancer management: (1) inadequacy prognostic markers; (2) lack of effective treatment options. In the clinical view of point, treatment of early diagnosed patients is relatively easy, which is often associated with a high cure rate. However, when the disease is more advanced, treatment options are limited and the failure rate is high. Clearly, discovery of new biomarkers and development of new treatments are challenging and development of specific inhibitors for targeting therapeutics to manage this progressive cancer is a critical clinical need. NG2/CSPG4 is a strong melanoma antigen that was identified 30 years ago. This marker is even more sensitive and specific than a commonly used melanoma marker, MART-1 (Melanoma Antigen Recognized by T cells) [98]. NG2/CSPG4 appears on approximately $85 \%$ of melanoma lesions and melanoma cell lines $[99,100]$. Recent data indicate that approximately $95 \%$ of primary lesions stained for NG2/ CSPG4, approximately $86 \%$ of metastatic lesions were NG2/CSPG4 positive [101] and the level of its expression is dramatically higher in metastatic lesions than non metastatic ones [38], suggesting that NG2/
CSPG4 may be a metastatic indicator in disseminated melanoma. As metastatic lesions display unusual spindle cell morphology which lacks the common clinical and histological characteristics, the use of NG2/ CSPG4 in diagnosis could be potentially very useful. Collectively, NG2/ CSPG4 highly expresses in melanomas than normal tissues, suggesting that it would be a useful biomarker for melanoma [102-105] and more hope for treatment of this advanced cancer.

Glioblastoma (GMB): GBM is highly lethal brain malignant cancer and is also related to angiogenesis. Brain is made up of numerous cell types that interact with cell-cell, cell-matrix contacts via soluble and insoluble signaling molecules. During angiogenesis in developmental brain, NG2/CSPG4 locates in the cell matrix and widely expressed by PCs as early as embryonic day 10-12 (E10-12) [23,106]. In the GBM, Shoshan and co-workers demonstrated NG2/CSPG4 expression in one out of five GBM [107], whilst others showed moderate to high expression in 6 out of 14 GBM biopsies and confrontation edge [77]. Xenografted NG2/CSPG4 overexpressing GBM cell lines resulted in increased angiogenesis and vascular permeability compared to NG2/CSPG4 negative cancers. Some results in 74 GBM biopsies demonstrated that NG2/CSPG4 was highly expressed on angiogenic vessels in $50 \%$ of GBM patients that are associated with significantly shorter survival outcomes. This effect on poor survival was independent of age at diagnosis and treatment received; suggesting that the role of NG2/CSPG4 in blood vessel development is extremely relevant to GBM progression. In addition, the PCs in the GBM attracted by PDGF-BB that is released from ECs and migrated into the sites where growth and proliferation were occurred [108]. The close apposition of PCs to ECs indicates a seminal role during angiogenesis [109]. As a cell surface component of PCs, NG2/CSPG4 is adequately positioned to sequester angiostatin, which otherwise would be available to inhibit proliferation and migration of ECs [110]. These observations suggest that targeting NG2/CSPG4 to abrogate the effect of NG2/CSPG4 in the GBM may significantly reduce angiogenesis and cancer growth.

Soft-tissue sarcomas (STS): The STS is a malignant cancer that is originated from mesenchymal tissue. Although good control and approximately $90 \%$ of STS patients present no clinical evidence of metastasis [110], approximately $50 \%$ of STS patients with high-grade sarcomas have less than 5-year life expectancy and die from metastasis [111]. Metastases and local cancer recurrences are recognized to be primary parameters affecting the STS which are void of definite molecular markers. Histological grading is adopted clinically as the sole parameter to gain information about a possible metastatic event following surgical removal of the primitive lesion [112]. Definition of metastatic potential from clinic is still based on histopathological parameters like grading, size, depth of local tissue infiltration. Hence, there is a strong need to identify more up-to-date effective targets to exploit in novel pharmacological and biological therapeutic modalities to control this type of cancer. Although proposed the prognostic importance of a number of clinical and histopathological markers more concrete genetic/molecular factors defining prognosis in STS patients still remain unavailable to clinicians [113-117]. The functional property and hypothesized role of NG2/CSPG4 in malignant progression have prompted scientists to investigate whether NG2/ CSPG4 is (over) expressed in STS, whether its expression pattern may provide relevant clinical information and whether NG2/CSPG4 may be as a putative immunotherapeutic target in the STS. Several preclinical studies have evaluated the role of targeting NG2/CSPG4 in STS. Several studies have marked that amplification of NG2/CSPG4 in metastatic STS strongly correlated with patient survival. NG2/CSPG4 has been proved to surpass other recognized clinical parameters in the 
Citation: Zhang H, Bie P, Leida Z, Xia Z, Bai L (2014) NG2/CSPG4 Proteoglycan as a Novel Prognostic Indicator and Therapeutic Target in Malignant Cancer. J Stem Cell Res Ther 4: 171. doi:10.4172/2157-7633.1000171

prognostic definition of STS patients. Heterogeneicity of intralesional distribution of NG2/CSPG4 suggests that the proteoglycan may define particularly aggressive subsets of malignant cancer cells. However, it is obviously not yet technically possible to determine whether the same highly NG2/CSPG4-enriched STS cells of the primitive lesions, or their progenies, are actually the ones directly responsible for the formation of metastases. Notably, recent experimental findings on the ability of NG2/CSPG4 to confer the cells of highly malignant, potentially metastatic phenotype identify a discrete STS cell population for therapeutic targeting, suggesting that preclinical mechanistic study and clinical trials of NG2/CSPG4 should be going on in order to evaluate its prognostic indicator and therapeutic role so that the efficacy of the varied anti-angiogenesis agents targeting NG2/CSPG4 can be ultimately validated in the STS.

Liver and pancreatic cancers: Liver and pancreatic cancers are the gastrointestinal malignant cancers which are considered highly dependent upon angiogenesis. Patients with these cancers have few available treatment options. Thus, new treatments that block blood vessel formation may give hope for these cancer patients. NG2/CSPG4 proteoglycan has been reported to be expressed on Hepatic Stellate Cells (HSCs) in liver cancer and numerous reports support the concept that HSCs serve as PC functions in angiogenesis of liver cancer [118]. HSCs in the liver cancer such as Hepatocellular Carcinoma (HCC) are responsible for the remodeling and deposition of cancer-associated cell matrix that are involved in cancer cell activation and migration. Activation and migration of HSCs into cancer nodules appear to be essential requirements for HCC angiogenesis. HSCs are also response to hypoxia [119] for a proangiogenic microenvironment creation, facilitating EC recruitment and survival during hepatic metastasis transition from an avascular to a vascular stage. It has been demonstrated that the MSCs have a phenotype resembling to the activated HSC cell line. Immunophenotypic analysis has further showed that HSC cell line is positive for activated HSC markers ( $\alpha$-SMA, GFAP, nestin, CD271) and MSC makers (CD73, CD105, CD44, CD29, CD90, HLA class-I, CD49e, CD166, CD146 and STRO-1) but negative for the endothelial (CD31), endothelial progenitor (CD133) markers and hematopoietic (CD45 and CD34) markers. Besides, the HSC cell line expresses NG2/ CSPG4 as well and is capable of stimulating new blood vessel formation [118]. Since NG2/CSPG4 has been very little examined in the context of liver and pancreatic cancers in human, we have spent several years to investigate the correlation of NG2/CSPG4 with multiple parameters obtained from clinic. We have collected eighty fresh clinical specimens from the patients with liver cancer and one hundred thirty from the patients with pancreatic cancers, and tested NG2/CSPG4 antigen with monoclonal antibodies. By using western blot and real time PCR (RTqPCR), we found significant increased expression of NG2/CSPG4 in both liver and pancreatic cancer areas as compared to adjacent tissues, particularly around vessels (Figure 1), indicating the implication of NG2/CSPG4-associated cell matrix to the different aspects of angiogenesis in liver and pancreatic cancers. Based on some supporting literatures, we hypothesize that NG2/CSPG4 promoting novel vessel formations in the two cancers may be also through PDGFR- $\beta$ signaling pathway in regulating angiogenesis affected by ECs and PCs. We believe that we are at the dawn of a new era in liver and pancreatic cancer therapeutics via targeting NG2/CSPG4.

\section{CSPG4/NG2 as an Immune Target for Cancers Treatment (Clinical Sense)}

To investigate novel anticancer therapies aimed at targeting both malignant cancer cells and their contexts in which they live remains an important challenge. Agents that target the cancer microenvironment represent an important strategy in cancer therapy. By expressing NG2/ CSPG4, the cancer can: (1) interact with growth factors to modulate adhesive, infiltration, proliferation and angiogenesis; (2) interact with integrin receptors and ECM components to mediate cellular motility as well as stimulate signal transduction pathways to avoid apoptosis. Questions by expressing NG2/CSPG4 remain to be answered is: (1) whether the therapeutic effects of targeting anti-NG2/CSPG4 by using Monoclonal Antibody ( $\mathrm{mAb}$ )-mediated immunotherapy can be enhanced to overcome the hurdles to efficient delivery and penetrate; (2) whether administrating small molecule inhibitors of NG2/CSPG4 or different signal transduction pathways mediated by the NG2/CSPG4 can be effectively targeted.

It is well known that the average mammal body contains tens of thousands of miles of vessels that permeate every tissue down to the microscopic level. This makes the vasculature a prime target for the treatment. As stated in many studies, the efficacy of different inhibitors in chemoprevention and the functional roles for blood vessels in early
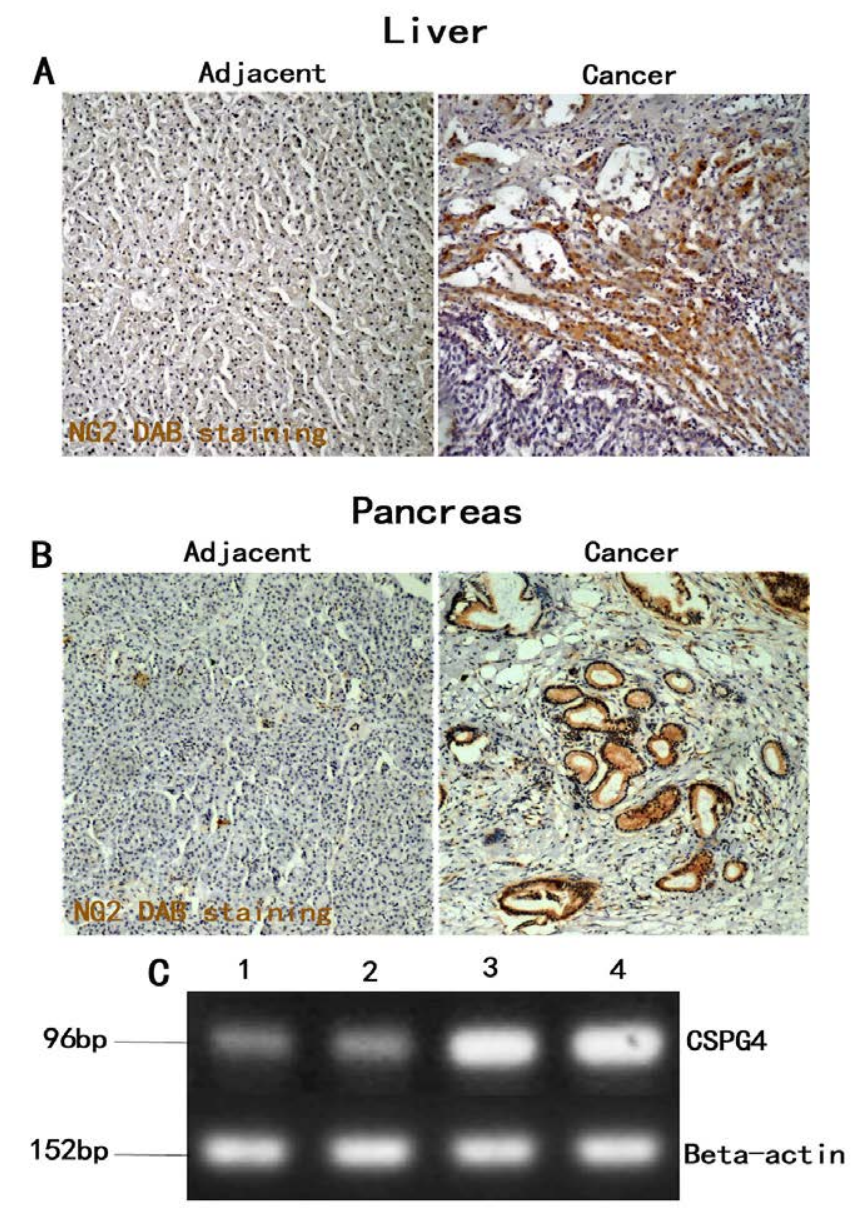

Figure 1: Different Pattern of Expression of NG2/CSPG4 in Human Liver and Pancreatic Cancer Biopsies detected by 3,3'-diaminobenzidine $(D A B)$ stainingand RT-qPCR. (A) DAB staining showed that highly positive staining of NG2 antigen in liver cancer, especially around blood vessels (right panel), while NG2 is negative or light positive in adjacent tissue of liver cancer (left panel). (B) Similar pattern showed in pancreatic cancer. (C) RT-qPCR showed highly expression of CSPG4 in metastatic tissues from liver (lane 3) and from pancreatic cancer patients (lane 4) compared to the adjacent liver tissue (lane 1 ) and the adjacent pancreatic tissue (lane 2) that all from the same patients. Original magnification, $\times 100$. 
neoplastic progression, invasion and malignant conversion events have clearly been demonstrated [120]. Unfortunately, results with inhibitors thus far have not been encouraging [121], thus, the novel efficient anticancer therapeutic tools are required. NG2/CSPG4 expression directly or indirectly enhances activation of multiple signaling pathways associated with oncogenic transformation. As be multifunctional, NG2/CSPG4 can interact with distinct key oncogenic pathways that may change dynamically during cancer progression. This may be one explanation for the high proportion of many malignant cancers that retain NG2/CSPG4 expression. Besides critical pathways that are also impacted by NG2/CSPG4 are the FAK with integrin, PI3K/AKT with NFKB and RTK downstream pathways of ERK 1/2) functions. Therefore, it is not surprising that NG2/CSPG4 will be a potential therapeutic target for the treatment of malignant cancers.

\section{NG2/CSPG4 mAb treatment}

Monoclonal Antibody (mAb)-based immunotherapy has been greatly investigated as a therapeutic strategy against malignancies [122]. NG2/CSPG4 antigen is a cell surface proteoglycan and has been shown to be expressed by not only cancer mass but also CSCs [39]. A body of studies in animal models or cancer patients has been verified that cancer cells can be inhibited by NG2/CSPG4-specific mAb, suggesting NG2/CSPG4 antigen as an immune target for the treatment of cancers. The mechanisms underlying anti-NG2/CSPG4-based immunotherapeutics may include: (1) complement-dependent one that membrane-bound cancer-associated NG2/CSPG4 antigen bound to $\mathrm{mAb}$ are recognized and destroyed by complement membrane attack complexes; (2) cell lysis of NG2/CSPG4-expressing cancer cells that is initiated by macrophages bearing $\mathrm{Fc}_{\mathrm{c}} \mathrm{III}$ receptors, natural killer cells, and neutrophils; (3) NG2/CSPG4-expressing cancer cell growth arrest and (4) NG2/CSPG4-expressing cancer cell apoptosis induced by mAb-specific antibody binding to the NG2/CSPG4 antigen to trigger signal transduction events [123].

Carbone $\mathrm{M}$ and colleagues have successfully targeted NG2/CSPG4 by using $\mathrm{mAb}$ for Malignant Mesothelioma (MM). They grafted the cancer cells in Severe Combined Immune Deficiency (SCID) mice and engineered to express the luciferase reporter gene, which were then monitored by imaging upon treatment with NG2/CSPG4 mAb. The significant inhibitive effect of anti-NG2/CSPG4 mAb on MM has been demonstrated [124]. Other particular studies which are performed in SCID animals have also demonstrated that these anti-NG2/CSPG4 mAb blocked NG2/CSPG4-regulated signaling pathways [125]. Poli A et al. [29] applied a combination of mAb immunotherapeutic strategy against NG2/CSPG4 with NK cells in preclinical animal models of GBM, which was showed to effectively diminish cancer cell proliferation, increase cellular apoptosis and prolong survival. Notably, NG2/CSPG4 offers several advantages over therapies that are strictly cancer-directed since therapies that target only cancer cells are limited by both the heterogeneous expression of NG2/CSPG4 within cancer and by the high rate of cancer cell mutation [126], while the host activated cell matrix vascular cells are relatively homogenous and lack the problems associated with drug resistance [127-130]. Although it is not clear whether NG2/CSPG4 antigen is internalized, other mechanisms can, in theory, still mediate the clinical benefits of $\mathrm{mAb}$-directed therapy. For example, membrane-bound cancer-associated NG2/CSPG4-expressing antigens bound to $\mathrm{mAb}$ are recognized and destroyed by complement membrane attack complexes; Cancer cells lysed by macrophages bearing Fc $\gamma$ III receptors, natural killer cells and neutrophils; and Cancer cell growth arrest and cancer cell apoptosis induced by $\mathrm{mAb}$ specific antibody binding to the NG2/CSPG4-expressing antigens that trigger signal transduction events in the cancer cells [131-133]. All the results traverse beyond the elucidation of NG2/CSPG4 as a therapeutic target. These NG2/CSPG4-associated functional properties of cancer cells could be inhibited by NG2/CSPG4-specific mAb. Moreover, CSCs can also be impaired by NG2/CSPG4-specific mAb. Although there is no complete consensus, perhaps the term CSCs should be regarded as the "weakness" of malignant cancers just like "the core" of bridges to situations wherein the CSCs is selectively attacked, rather than cancer mass attacked, targeted CSCs that drive cancer dying through CSCs. Today, although many researchers in CSC field have advanced their far enough researches still lack the specific target for cancers. The anticancer mass or CSC effects of NG2/CSPG4-specific mAb are likely to reflect the blocking of important migratory, mitogenic and survival signaling pathways in cancer cells. These observations indicate that NG2/CSPG4 is a promising new target to implement mAb-based immunotherapy of various types of cancers. Therefore, providing a proof of concept that targets NG2/CSPG4 by mAb may hold potential for the treatment of malignant cancers.

Although this treatment strategy is highly attractive, the therapeutic efficacy of mAb-directed therapies has been limited by several shortcomings [134]. For example, the loss of antigenic epitopes on cancer cells; the lack of cancer-specific antigens; antibody toxicity; failure of the large antibody complexes to cross the blood brain barrier; the high interstitial pressure leading to poor diffusion of antibodies into all parts of the cancer; the dehalogenation or removal of radioactive label from $\mathrm{mAb}$; the enzymatic removal of $\mathrm{mAb}$ from cancers and lack of $\mathrm{mAb}$ humanization. Thus, small peptides would be needed to overcome the disadvantages.

\section{NG2/CSPG4 peptides treatment}

In order to overcome mAb limitations, peptide-based anti-NG2/ CSPG4 therapy could be the optimized delivery. Small peptides may prove superior to antibodies in terms of penetration into cancers. More alluring would certainly be the approach of targeting cytoplasmic tails of cell surface-associated NG2/CSPG4. This process contributed would certainly be the approach events in malignant cancer cells.

Phage display of random peptide libraries has previously enabled isolation of peptides that successfully bind to cancer-associated NG2/ CSPG4 [135,136]. Evidence that NG2/CSPG4-binding decapeptides home directly to the angiogenic neovasculature of melanoma xenografts in mice have been developed [137]. The localization and accessibility of NG2/CSPG4 on PCs suggested a potential use of these vessel homing sequences for targeted delivery of therapeutic agents to malignant cancers. Effect on PC and ECs of NG2/CSPG4 also suggests that NG2/CSPG4-expressing PCs play an important role in controlling EC proliferation and vessel stabilization during angiogenesis in malignant cancers [138]. Thus, anticancer strategies targeting NG2/ CSPG4-expressing PCs in the angiogenic vasculature may complement the approaches targeting ECs. The peptides targeting NG2/CSPG4 could deliver therapeutic agents to the cancer cells and also their vasculature. Soldano F and colleagues generated a NG2/CSPG4specific single-chain antibody ( $\mathrm{scFv}-\mathrm{FcC} 21)$ to a viable NG2/CSPG4expressing CSC and demonstration inhibition of in vitro growth and migration of cancer cells and in vivo growth of cancer xenografts. These effects were mediated by inhibition of the activation of extracellular signal-regulated and focal adhesion kinase signaling pathways that are critical for CSC growth and migration. Their findings define the NG2/CSPG4-specific fully human scFv-FcC21 antibody peptide as a candidate therapeutic agent to target many types of cancers that express NG2/CSPG4. Several clinical cases of cancer patients treated with anti- 
idiotypic antibodies that mimic NG2/CSPG4 antigen demonstrate a statistically significant increase in survival. The effect of the antiidiotypic antibodies in survival has been shown to induce HLA class 1-restricted NG2/CSPG4-specific CTL [137] that was a viable option for the treatment of cancers. A recent study in an animal model have showed that the efficacy for adoptively transferred CTLs engineered to express antibodies against NG2/CSPG4 antigens in the treatment of NG2/CSPG4-expressing melanomas is satifactory to block growth and promoted regression of NG2/CSPG4-expressing cancers.

In sum, immunotherapeutic targeting of NG2/CSPG4 is becoming a fruitful area, when considering direct immunotargeting and contemplating adaptive (vaccination-based) immunotherapeutic strategies. A better understanding of the importance of NG2/CSPG4 contribution in malignant cancers will incite the future evolvement of targeted therapeutic agents specifically and directly against NG2/ CSPG4. The successful outcome of recent clinical trials that NG2/ CSPG4 is used as an immunotherapeutic target confirms this potential and provides a lead for the future development of NG2/CSPG4directed modalities to treat malignant cancers.

\section{RNA interference NG2/CSPG4 treatment}

Despite considerable hurdles to overcome, it seems likely that RNA interference (RNAi) may find a place alongside conventional approaches in treatment of malignant cancers [138]. RNAi is a process whereby small, noncoding double stranded RNAs posttranscriptionally silence specific genes including small interfering RNA (siRNA) and small hairpin RNA (shRNA). The use of RNAi to target specific cellular transcripts essentially hijacks the endogenous RNAi pathway, which can potentially be saturated. It is a highly conserved mechanism that has been first recognized as an antiviral immune response in plants to protect against random transposable elements [139]. There are two key challenges for the use of RNAi in therapeutics: (1) avoiding off-target effects; (2) ensuring efficient delivery.

siRNAs are double stranded molecules and taken up by binding to serum proteins. Once antigen presents in cancers, siRNA must be transported across the capillary walls, and penetrate the cancer cell matrix to reach the cancer cells. Transport through the cancer cell matrix involves both diffusion and convection owing to the absence of osmotic or pressure gradients in cancers. Moreover, siRNA must travel through the vasculature to reach its target, a functional and well distributed vascular network facilitating the cancer blood flow is necessary for efficient drug delivery [140]. From a clinical point of view, this represents a therapeutic quagmire. As all perivascular cells along arterioles express NG2/CSPG4, therapeutic strategies targeting it in cancers must involve local delivery. Some of the deliveries need to be taken into account to ensure an adequate biodistribution within the cancer bed. Gene silencing may be limited by their transient effects and restricted by the rate of cell division. It is demonstrated that the expression of NG2/CSPG4 results in significant resistance to cancer cell death induced by using siRNA, which leads to their increased sensitivity to apoptotic stimuli regents such as tumor necrosis factor (TNF)- $a$. Stable downregulation of NG2/CSPG4 in different cancers has been demonstrated to lead to marked reduction of cancer growth rates and volumes. The growth of cancers is considerably retarded after TNF- $\alpha$ treatment, indicating that the cancer sensitivity to cell death mediators can be restored by siRNA gene silencing. Another experiment indicates that interplays of NG2/CSPG4 and collagen type VI are putatively involved in the cancer cell matrix control of cancer engraftment and local expansion. It has been shown that NG2/CSPG4- associated malignancy is corroborated by the diverse carcinogenic behavior of immune selected NG2/CSPG4-expressing and NG2deficient cell subsets, the RNAi-mediated knockdown of endogenous $\mathrm{NG} 2$, and the ectopic transduction of full-length or deletion constructs of NG2/CSPG4. Combination of usage of dominant-negative NG2/ CSPG4 mutant cells and purified domain fragments of the collagen provide evidence to pinpoint the reciprocal binding sites and assert the importance of this molecular interaction in the control of cancer cell adhesion and motility.

Similarly, in vivo experiments have showed that the direct injection of lentivirus encoding a NG2/CSPG4 shRNA into cancer xenografts results in cancer regression [141], demonstrating the effect of targeting NG2/CSPG4 expression with viral delivery of shRNA or treating the cancers with injection of $\mathrm{mAb}$ on reducing blood vessel formation in cancer xenografts. As vascular PCs express NG2/CSPG4, shRNA may block neoangiogenesis by limiting PC proliferation or viability. This notion is supported by studies in the NG2/CSPG4 knockout mice to show a reduction in pathological angiogenesis that correlates with a loss of proliferation of vascular PCs [34]. Similar to the consequences of genetic deletion of NG2/CSPG4 in mouse GBM susceptibility model showed to be lack cancer-associated PCs. NG2/CSPG4 shed by cancer PCs has also been shown to stimulate motility in ECs involved in angiogenesis through binding of integrin family, but effects is abrogated by antibody against NG2/CSPG4, suggesting that targeting NG2/CSPG4 could have direct effects on cancer cell signaling on cancer-matrix cell interactions to promote cancer proliferation and angiogenesis. It is well known that chemoresistance is a major factor in the successful treatment of malignant cancers although cancers in many patients initially respond to therapy, but resistance to chemotherapy develops over time and cancer progresses. NG2/CSPG4 may influence drug resistance. For example, the development of drug resistance in melanoma appears to be particularly linked to the use of single-target inhibitor, such as BRAFV600E. The ability of anti-NG2/CSPG4 mAb to prolong the growth inhibitory effects of PLX4032, a BRAFV600E inhibitor, on melanoma cell lines in culture provides direct evidence for a role of this proteoglycan in promoting chemoresistance [58].

Taken as a whole, all data described in this section provide a rationale for targeting NG2/CSPG4 as an adjuvant therapy for malignant cancers using either an immune-based therapeutic approach or development of small molecule inhibitors against NG2/CSPG4.

\section{Future Directions}

Over the past $30 \mathrm{yr}$, much work has gone into documenting NG2/ CSPG4 expression in diverse malignant cancers and increasing an understanding of its function in cancer cell biology. We have here provided a number of examples published within the last year to implicate NG2/CSPG4 in malignant cancers for the regulation of cancer cell adhesion, migration, proliferation and angiogenesis. Although evidence still remains circumstantial, many studies indicate that NG2/ CSPG4 can affect the biological activity of component molecules involved in cancer progress through highly specific cell-cell, cell-matrix interactions. The challenge for the future in the study of malignant cancers would be to understand the molecular mechanisms underlyin aberrant expression of NG2/CSPG4 and identify the structural motifs that facilitate its targeting.

\section{Acknowledgements}

This work was supported by grants to Lianhua Bai from the National Natural Science Foundation of China (NSFC) 81170425. Authors appreciate Dr. Jin Sun and Dr. Lele Lu provided the images. 
Citation: Zhang H, Bie P, Leida Z, Xia Z, Bai L (2014) NG2/CSPG4 Proteoglycan as a Novel Prognostic Indicator and Therapeutic Target in Malignant Cancer. J Stem Cell Res Ther 4: 171. doi:10.4172/2157-7633.1000171

\section{References}

1. Yamanaka O, Sumioka T, Saika S (2014) The role of extracellular matrix in corneal wound healing. Cornea 2013; 32: s43-s45-retracted. Cornea 33: 100.

2. Natali PG, Segatto O, Zupi G, Cavaliere R, Giacomini P, et al. (1983) Isolation of viable melanoma cells from surgically removed lesions using dishes coated with monoclonal antibody to a high molecular weight melanoma associated antigen. J Immunol Methods 62: 337-346.

3. Stallcup WB (1981) The NG2 antigen, a putative lineage marker: immunofluorescent localization in primary cultures of rat brain. DevBiol 83: 154-165.

4. Nishiyama A, Dahlin KJ, Prince JT, Johnstone SR, Stallcup WB (1991) The primary structure of NG2, a novel membrane-spanning proteoglycan. $\mathrm{J}$ Cell Biol 114: 359-371.

5. Bergles DE, Jabs R, Steinhäuser C (2010) Neuron-glia synapses in the brain. Brain Res Rev 63: 130-137.

6. Aya-ay J, Mayer J, Eakin AK, Muffly BG, Anello M, et al. (2005) The effect of hypoxic-ischemic brain injury in perinatal rats on the abundance and proteolysis of brevican and NG2. ExpNeurol 193: 149-162.

7. Wilson BS, Imai K, Natali PG, Ferrone S (1981) Distribution and molecular characterization of a cell-surface and a cytoplasmic antigen detectable in human melanoma cells with monoclonal antibodies. Int J Cancer 28: 293-300.

8. lida J, Wilhelmson KL, $\mathrm{Ng} \mathrm{J}$, Lee P, Morrison C, et al. (2007) Cell surface chondroitin sulfate glycosaminoglycan in melanoma: role in the activation of pro-MMP-2 (pro-gelatinase A). Biochem J 403: 553-563.

9. Garusi E, Rossi S, Perris R (2012) Antithetic roles of proteoglycans in cancer Cell Mol Life Sci 69: 553-579.

10. Chekenya M, Immervoll H (2007) NG2/HMP proteoglycan as a cancer therapeutic target. Methods MolBiol 361: 93-117.

11. Stegmüller J, Schneider S, Hellwig A, Garwood J, Trotter J (2002) AN2, the mouse homologue of NG2, is a surface antigen on glial precursor cells implicated in control of cell migration. J Neurocytol 31: 497-505.

12. Schlingemann RO, Rietveld FJ, Kwaspen F, van de Kerkhof PC, de Waal RM et al. (1991) Differential expression of markers for endothelial cells, pericytes, and basal lamina in the microvasculature of tumors and granulation tissue. Am J Pathol 138: 1335-1347.

13. Schneider S, Bosse F, D'Urso D, Muller H, Sereda MW, et al. (2001) The AN2 protein is a novel marker for the Schwann cell lineage expressed by immature and nonmyelinating Schwann cells. J Neurosci 21: 920-933.

14. Ghali L, Wong ST, Tidman N, Quinn A, Philpott MP, et al. (2004) Epidermal and hair follicle progenitor cells express melanoma-associated chondroitin sulfate proteoglycan core protein. J Invest Dermatol 122: 433-442.

15. Legg J, Jensen UB, Broad S, Leigh I, Watt FM (2003) Role of melanoma chondroitin sulphate proteoglycan in patterning stem cells in human interfollicular epidermis. Development 130: 6049-6063.

16. Midwood KS, Salter DM (1998) Expression of NG2/human melanoma proteoglycan in human adult articular chondrocytes. Osteoarthritis Cartilage 6: 297-305.

17. Tordsson JM, Ohlsson LG, Abrahmsén LB, Karlström PJ, Lando PA, et al. (2000) Phage-selected primate antibodies fused to superantigens for immunotherapy of malignant melanoma. Cancer Immunollmmunother 48: 691-702.

18. Schlingemann RO, Rietveld FJ, de Waal RM, Bradley NJ, Skene Al, et al. (1990) Leukocyte antigen CD34 is expressed by a subset of cultured endothelial cells and on endothelial abluminalmicroprocesses in the tumor stroma. Lab Invest 62: 690-696.

19. Petrini S, Tessa A, Carrozzo R, Verardo M, Pierini R, et al. (2003) Human melanoma/NG2 chondroitin sulfate proteoglycan is expressed in the sarcolemma of postnatal human skeletal myofibers. Abnormal expression in merosin-negative and Duchenne muscular dystrophies. Mol Cell Neurosci 23 : $219-231$

20. Linehan SA, Martínez-Pomares L, Stahl PD, Gordon S (1999) Mannose receptor and its putative ligands in normal murine lymphoid and nonlymphoid organs: In situ expression of mannose receptor by selected macrophages, endothelial cells, perivascular microglia, and mesangial cells, but not dendritic cells. J Exp Med 189: 1961-1972.
21. Di Bello IC, Dawson MR, Levine JM, Reynolds R (1999) Generation of oligodendroglial progenitors in acute inflammatory demyelinating lesions of the rat brain stem is associated with demyelination rather than inflammation. J Neurocytol 28: 365-381.

22. Nishiyama A, Lin XH, Giese N, Heldin CH, Stallcup WB (1996) Interaction between NG2 proteoglycan and PDGF alpha-receptor on O2A progenitor cells is required for optimal response to PDGF. J Neurosci Res 43: 315-330.

23. Keirstead HS, Levine JM, Blakemore WF (1998) Response of the oligodendrocyte progenitor cell population (defined by NG2 labelling) to demyelination of the adult spinal cord. Glia 22: 161-170.

24. Kozanoglu I, Boga C, Ozdogu H, Sozer O, Maytalman E, et al. (2009) Human bone marrow mesenchymal cells express NG2: possible increase in discriminative ability of flow cytometry during mesenchymal stromal cell identification. Cytotherapy. 11: 527-533.

25. Fukushi J, Inatani M, Yamaguchi Y, Stallcup WB (2003) Expression of NG2 proteoglycan during endochondral and intramembranous ossification. DevDyn 228: $143-148$.

26. Nishiyama A, Dahlin KJ, Stallcup WB (1991) The expression of NG2 proteoglycan in the developing rat limb. Development 111: 933-944.

27. Ozerdem U, Monosov E, Stallcup WB (2002) NG2 proteoglycan expression by pericytes in pathological microvasculature. Microvasc Res 63: 129-134.

28. Zhang H, Zhang X, Bie P, Miller RH, Bai L (2013) Adult NG2-Expressing Cells in Multiple Organs: A Novel Progenitor in Regenerative Medicine. J Genet Syndr Gene Ther S3: 008.

29. Crisan M, Yap S, Casteilla L, Chen CW, Corselli M, et al. (2008) A perivascular origin for mesenchymal stem cells in multiple human organs. Cell Stem Cell 3: 301-313.

30. Poli A, Wang J, Domingues O, Planagumà J, Yan T, et al. (2013) Targeting glioblastoma with NK cells and mAb against NG2/CSPG4 prolongs animal survival. Oncotarget 4: 1527-1546.

31. Léger O, Jackson E, Dean C (1995) Primary structure of the variable regions encoding antibody to NG2, a tumour-specific antigen on the rat chondrosarcoma HSN. Correlation of idiotypic specificities with amino acid sequences. Mollmmunol 32: 697-709.

32. Wang X, Wang Y, Yu L, Sakakura K, Visus C, et al. (2010) CSPG4 in cancer multiple roles. CurrMol Med 10: 419-429.

33. Hsu NC, Nien PY, Yokoyama KK, Chu PY, Hou MF (2013) High chondroitin sulfate proteoglycan 4 expression correlates with poor outcome in patients with breast cancer. BiochemBiophys Res Commun 441: 514-518.

34. Cattaruzza S, Nicolosi PA, Braghetta P, Pazzaglia L, Benassi MS, et al (2013) NG2/CSPG4-collagen type VI interplays putatively involved in the microenvironmental control of tumour engraftment and local expansion. J Mol Cell Biol 5: 176-193.

35. Ozerdem U, Stallcup WB (2003) Early contribution of pericytes to angiogenic sprouting and tube formation. Angiogenesis 6: 241-249.

36. Kageshita T, Nakamura T, Yamada M, Kuriya N, Arao T, et al. (1991) Differentia expression of melanoma associated antigens in acrallentiginous melanoma and in nodular melanoma lesions. Cancer Res 51: 1726-1732.

37. Nishi H, Inoue $Y$, Kageshita T, Takata M, Ihn H (2010) The expression of human high molecular weight melanoma-associated antigen in acrallentiginous melanoma. Biosci Trends 4: 86-89.

38. Svendsen A, Verhoeff JJ, Immervoll H, Brøgger JC, Kmiecik J, et al. (2011) Expression of the progenitor marker NG2/CSPG4 predicts poor survival and resistance to ionising radiation in glioblastoma. ActaNeuropathol 122: 495-510.

39. Bao S, Wu Q, McLendon RE, Hao Y, Shi Q, et al. (2006) Glioma stem cells promote radioresistance by preferential activation of the DNA damage response. Nature 444: 756-760.

40. Benassi MS, Pazzaglia L, Chiechi A, Alberghini M, Conti A, et al. (2009) NG2 expression predicts the metastasis formation in soft-tissue sarcoma patients. $J$ Orthop Res 27: 135-140.

41. Petrovici K, Graf M, Hecht K, Reif S, Pfister K, et al. (2010) Use of NG2 (7.1) in $\mathrm{AML}$ as a tumor marker and its association with a poor prognosis. Cance Genomics Proteomics 7: 173-180.

42. Chiquet-Ehrismann R, Tucker RP (2004) Connective tissues: signalling by tenascins. Int J Biochem Cell Biol 36: 1085-1089. 
Citation: Zhang H, Bie P, Leida Z, Xia Z, Bai L (2014) NG2/CSPG4 Proteoglycan as a Novel Prognostic Indicator and Therapeutic Target in Malignant Cancer. J Stem Cell Res Ther 4: 171. doi:10.4172/2157-7633.1000171

43. Hynes RO (2002) Integrins: bidirectional, allosteric signaling machines. Cell 110: 673-687.

44. Humphries MJ (2000) Integrin cell adhesion receptors and the concept of agonism. Trends PharmacolSci 21: 29-32.

45. Morra L, Moch H (2011) Periostin expression and epithelial-mesenchymal transition in cancer: a review and an update. Virchows Arch 459: 465-475.

46. Gunia S, Jain A, Koch S, Denzinger S, Götz S, et al. (2013) Periostin expression correlates with pT-stage, grading and tumour size, and independently predicts cancer-specific survival in surgically treated penile squamous cell carcinomas. J ClinPathol 66: 297-301.

47. Brandner JM, Haass NK (2013) Melanoma's connections to the tumour microenvironment. Pathology 45: 443-452.

48. Midwood KS, Salter DM (2001) NG2/HMPG modulation of human articular chondrocyte adhesion to type VI collagen is lost in osteoarthritis. J Pathol 195: 631-635

49. lida J, Meijne AM, Spiro RC, Roos E, Furcht LT, et al. (1995) Spreading and focal contact formation of human melanoma cells in response to the stimulation of both melanoma-associated proteoglycan (NG2) and alpha 4 beta 1 integrin. Cancer Res 55: 2177-2185.

50. Tanaka K, Nogawa S, Ito D, Suzuki S, Dembo T, et al. (2001) Activation of NG2-positive oligodendrocyte progenitor cells during post-ischemic reperfusion in the rat brain. Neuroreport 12: 2169-2174.

51. Doane KJ, Howell SJ, Birk DE (1998) Identification and functional characterization of two type $\mathrm{VI}$ collagen receptors, alpha 3 beta 1 integrin and NG2, during avian corneal stromal development. Invest Ophthalmol Vis Sci 39: $263-275$.

52. Gramann M, Wendler O, Haeberle L, Schick B (2009) Prominent collagen type VI expression in juvenile angiofibromas. Histochem Cell Biol 131: 155-164

53. Joo NE, Watanabe T, Chen C, Chekenya M, Stallcup WB, et al. (2008) NG2, a novel proapoptotic receptor, opposes integrin alpha4 to mediate anoikis through PKCalpha-dependent suppression of FAK phosphorylation. Cell Death Differ 15: 899-907.

54. Chekenya M, Krakstad C, Svendsen A, Netland IA, Staalesen V, et al. (2008) The progenitor cell marker NG2/MPG promotes chemoresistance by activation of integrin-dependent PI3K/Akt signaling. Oncogene 27: 5182-5194.

55. lida J, Dorchak J, Lehman JR, Clancy R, Luo C, et al. (2012) FH535 inhibited migration and growth of breast cancer cells. PLoS One 7: e44418.

56. Price MA, Colvin Wanshura LE, Yang J, Carlson J, Xiang B, et al. (2011) CSPG4, a potential therapeutic target, facilitates malignant progression of melanoma. Pigment Cell Melanoma Res 24: 1148-1157.

57. Mueller MM, Fusenig NE (2004) Friends or foes - bipolar effects of the tumourstroma in cancer. Nat Rev Cancer 4: 839-849.

58. Uhrbom L, Hesselager G, Ostman A, Nistér M, Westermark B (2000) Dependence of autocrine growth factor stimulation in platelet-derived growth factor-B-induced mouse brain tumor cells. Int J Cancer 85: 398-406.

59. Bhowmick NA, Moses HL (2005) Tumor-stroma interactions. Curr Opin Genet Dev 15: 97-101.

60. Yayon A, Klagsbrun M, Esko JD, Leder P, Ornitz DM (1991) Cell surface, heparin-like molecules are required for binding of basic fibroblast growth factor to its high affinity receptor. Cell $64: 841-848$.

61. Gitay-Goren H, Soker S, Vlodavsky I, Neufeld G (1992) The binding of vascular endothelial growth factor to its receptors is dependent on cell surfaceassociated heparin-like molecules. J BiolChem 267: 6093-6098.

62. Rapraeger AC (1995) In the clutches of proteoglycans: how does heparan sulfate regulate FGF binding? ChemBiol 2: 645-649.

63. Goretzki L, Burg MA, Grako KA, Stallcup WB (1999) High-affinity binding of basic fibroblast growth factor and platelet-derived growth factor-AA to the core protein of the NG2 proteoglycan. J BiolChem 274: 16831-16837.

64. Wang D, Tang F, Wang S, Jiang Z, Zhang L (2012) Preclinical anti-angiogenesis and anti-tumor activity of SIM010603, an oral, multi-targets receptor tyrosine kinases inhibitor. Cancer ChemotherPharmacol 69: 173-183.

65. Tlsty TD (2001) Stromal cells can contribute oncogenic signals. Semin Cancer Biol 11: 97-104.
66. Radisky D, Hagios C, Bissell MJ (2001) Tumors are unique organs defined by abnormal signaling and context. Semin Cancer Biol 11: 87-95.

67. Cattaruzza S, Ozerdem U, Denzel M, Ranscht B, Bulian P, et al. (2013) Multivalent proteoglycan modulation of FGF mitogenic responses in perivascular cells. Angiogenesis 16: 309-327.

68. Bansal R, Pfeiffer SE (1997) FGF-2 converts mature oligodendrocytes to a novel phenotype. J Neurosci Res 50: 215-228.

69. Chekenya M, Pilkington GJ (2002) NG2 precursor cells in neoplasia: functional, histogenesis and therapeutic implications for malignant brain tumours. Neurocytol 31: 507-521.

70. Song S, Ewald AJ, Stallcup W, Werb Z, Bergers G (2005) PDGFRbeta+ perivascular progenitor cells in tumoursregulatepericyte differentiation and vascular survival. Nat Cell Biol 7: 870-879.

71. Grako KA, Stallcup WB (1995) Participation of the NG2 proteoglycan in rat aortic smooth muscle cell responses to platelet-derived growth factor. Exp Cell Res 221: 231-240.

72. Woenne EC, Lederle W, Zwick S, Palmowski M, Krell H, et al. (2010) MMP inhibition blocks fibroblast-dependent skin cancer invasion, reduces vascularization and alters VEGF-A and PDGF-BB expression. Anticancer Res 30: 703-711.

73. Scheef EA, Sorenson CM, Sheibani N (2009) Attenuation of proliferation and migration of retinal pericytes in the absence of thrombospondin-1. Am J Physiol Cell Physiol 296: C724-734.

74. Goretzki L, Burg MA, Grako KA, Stallcup WB (1999) High-affinity binding of basic fibroblast growth factor and platelet-derived growth factor-AA to the core protein of the NG2 proteoglycan. J BiolChem 274: 16831-16837.

75. Paulus W, Roggendorf W, Schuppan D (1988) Immunohistochemical investigation of collagen subtypes in human glioblastomas. Virchows Arch A PatholAnatHistopathol 413: 325-332.

76. Tigges U, Komatsu M, Stallcup WB (2013) Adventitial pericyte progenitor mesenchymal stem cells participate in the restenotic response to arterial injury. J Vasc Res 50: 134-144.

77. Hellberg C, Ostman A, Heldin CH (2010) PDGF and vessel maturation. Recent Results Cancer Res 180: 103-114.

78. Chekenya M, Enger PØ, Thorsen F, Tysnes BB, Al-Sarraj S, et al. (2002) The glial precursor proteoglycan, NG2, is expressed on tumourneovasculature by vascular pericytes in human malignant brain tumours. NeuropatholAppINeurobio 28: $367-380$.

79. Brekke C, Lundervold A, Enger $P \varnothing$, Brekken C, Stålsett $E$, et al. (2006) NG2 expression regulates vascular morphology and function in human brain tumours. Neuroimage 29: 965-976.

80. Burg MA, Grako KA, Stallcup WB (1998) Expression of the NG2 proteoglycan enhances the growth and metastatic properties of melanoma cells. J Cell Physiol 177: 299-312.

81. Turnbull JE, Fernig DG, Ke Y, Wilkinson MC, Gallagher JT (1992) Identification of the basic fibroblast growth factor binding sequence in fibroblast heparan sulfate. J BiolChem 267: 10337-10341.

82. Andres JL, Rönnstrand L, Cheifetz S, Massagué J (1991) Purification of the transforming growth factor-beta (TGF-beta) binding proteoglycan betaglycan. J BiolChem 266: 23282-23287.

83. Andres JL, DeFalcis D, Noda M, Massagué J (1992) Binding of two growth factor families to separate domains of the proteoglycan betaglycan. J BiolChem 267: 5927-5930.

84. Kociński M, Klepaczko A, Materka A, Chekenya M, Lundervold A (2012) 3D image texture analysis of simulated and real-world vascular trees. Comput Methods Programs Biomed 107: 140-154.

85. Wang J, Svendsen A, Kmiecik J, Immervoll $\mathrm{H}$, Skaftnesmo $\mathrm{KO}$, et al (2011) Targeting the NG2/CSPG4 proteoglycan retards tumour growth and angiogenesis in preclinical models of GBM and melanoma. PLoS One 6: e23062.

86. Folkman J (1971) Tumor angiogenesis: therapeutic implications. N Engl J Med 285: $1182-1186$

87. Feige JJ, Bailly S (2000) [Molecular bases of angiogenesis]. Bull AcadNatl Med 184: 537-544. 
Citation: Zhang H, Bie P, Leida Z, Xia Z, Bai L (2014) NG2/CSPG4 Proteoglycan as a Novel Prognostic Indicator and Therapeutic Target in Malignant Cancer. J Stem Cell Res Ther 4: 171. doi:10.4172/2157-7633.1000171

88. Baluk P, Hashizume H, McDonald DM (2005) Cellular abnormalities of blood vessels as targets in cancer. CurrOpin Genet Dev 15: 102-111.

89. Enge M, Bjarnegård M, Gerhardt H, Gustafsson E, Kalén M, et al. (2002) Endothelium-specific platelet-derived growth factor-B ablation mimics diabetic retinopathy. EMBO J 21: 4307-4316.

90. Tallquist MD, French WJ, Soriano P (2003) Additive effects of PDGF receptor beta signaling pathways in vascular smooth muscle cell development. PLoSBio 1: E52.

91. Cipriani P, Marrelli A, Benedetto PD, Liakouli V, Carubbi F, et al. (2013) Scleroderma Mesenchymal Stem Cells display a different phenotype from healthy controls; implications for regenerative medicine. Angiogenesis 16: 595607.

92. Gibby K, You WK, Kadoya K, Helgadottir H, Young LJ, et al. (2012) Early vascular deficits are correlated with delayed mammary tumorigenesis in the MMTV-PyMT transgenic mouse following genetic ablation of the NG2 proteoglycan. Breast Cancer Res 14:R67.

93. Nasarre P, Thomas M, Kruse K, Helfrich I, Wolter V (2009) Host-derived angiopoietin-2 affects early stages of tumor development and vessel maturation but is dispensable for later stages of tumor growth. Cancer Res 69: 1324-1333.

94. Warren BA, Shubik P (1966) The growth of the blood supply to melanoma transplants in the hamster cheek pouch. Lab Invest 15: 464-478.

95. Solesvik OV, Rofstad EK, Brustad T (1982) Vascular structure of five human malignant melanomas grown in athymic nude mice. Br J Cancer 46: 557-567.

96. Srivastava A, Laidler P, Hughes LE, Woodcock J, Shedden EJ (1986) Neovascularization in human cutaneous melanoma: a quantitative morphological and Doppler ultrasound study. Eur J Cancer ClinOncol 22: 12051209.

97. Srivastava A, Laidler P, Davies RP, Horgan K, Hughes LE (1988) The prognostic significance of tumor vascularity in intermediate-thickness $(0.76-4.0$ $\mathrm{mm}$ thick) skin melanoma. A quantitative histologic study. Am J Pathol 133 419-423.

98. Goto Y, Ferrone S, Arigami T, Kitago M, Tanemura A, et al. (2008) Human high molecular weight-melanoma-associated antigen: utility for detection of metastatic melanoma in sentinel lymph nodes. Clin Cancer Res 14: 3401-3407.

99. Giacomini P, Natali P, Ferrone S (1985) Analysis of the interaction between a human high molecular weight melanoma-associated antigen and the monoclonal antibodies to three distinct antigenic determinants. J Immunol. 135: 696-702.

100. Natali PG, Viora M, Nicotra MR, Giacomini P, Bigotti A, et al. (1983) Antigenic heterogeneity of skin tumors of nonmelanocyte origin: analysis with monoclonal antibodies to tumor-associated antigens and to histocompatibility antigens. J Natl Cancer Inst 71: 439-447.

101. Goto Y, Arigami T, Murali R, Scolyer RA, Tanemura A, et al. (2010) High molecular weight-melanoma-associated antigen as a biomarker of desmoplastic melanoma. Pigment Cell Melanoma Res 23: 137-140.

102. Ulmer A, Schmidt-Kittler O, Fischer J, Ellwanger U, Rassner G, et al. (2004) Immunomagnetic enrichment, genomic characterization, and prognostic impact of circulating melanoma cells. Clin Cancer Res 10: 531-537.

103. Suesskind D, Ulmer A, Schiebel U, Fierlbeck G, Spitzer B, et al. (2011) Circulating melanoma cells in peripheral blood of patients with uveal melanoma before and after different therapies and association with prognostic parameters: a pilot study. ActaOphthalmol 89: 17-24.

104. Kitago M, Koyanagi K, Nakamura T, Goto Y, Faries M, et al. (2009) mRNA expression and BRAF mutation in circulating melanoma cells isolated from peripheral blood with high molecular weight melanoma-associated antigenspecific monoclonal antibody beads. Clin Chem. 55: 757-764.

105. Sakaizawa K, Goto Y, Kiniwa Y, Uchiyama A, Harada K, et al. (2012) Mutation analysis of BRAF and KIT in circulating melanoma cells at the single cell level. $\mathrm{Br} J$ Cancer 106: 939-946

106. Shee WL, Ong WY, Lim TM (1998) Distribution of perlecan in mouse hippocampus following intracerebroventricularkainate injections. Brain Res 799: $292-300$

107. Shoshan Y, Nishiyama A, Chang A, Mörk S, Barnett GH, et al. (1999) Expression of oligodendrocyte progenitor cell antigens by gliomas: implications for the histogenesis of brain tumors. ProcNatlAcadSci U S A 96: 10361-10366.
108. Orlidge A, D'Amore PA (1987) Inhibition of capillary endothelial cell growth by pericytes and smooth muscle cells. J Cell Biol 105: 1455-1462.

109. Goretzki L, Lombardo CR, Stallcup WB (2000) Binding of the NG2 proteoglycan to kringle domains modulates the functional properties of angiostatin and plasmin(ogen). J BiolChem 275: 28625-28633.

110. Rosenberg SA, Tepper J, Glatstein E, Costa J, Young R, et al. (1983) Prospective randomized evaluation of adjuvant chemotherapy in adults with soft tissue sarcomas of the extremities. Cancer 52: 424-434.

111. Cardona K, Williams R, Movva S (2013) Multimodality therapy for advanced or metastatic sarcoma. CurrProbl Cancer 37: 74-86.

112. Coindre JM, Terrier P, Guillou L, Le Doussal V, Collin F, et al. (2001) Predictive value of grade for metastasis development in the main histologic types of adult soft tissue sarcomas: a study of 1240 patients from the French Federation of Cancer Centers Sarcoma Group. Cancer 91: 1914-1926.

113. Kawaguchi K, Oda Y, Saito T, Yamamoto H, Tamiya S, et al. (2003) Mechanisms of inactivation of the p16INK4a gene in leiomyosarcoma of sof tissue: decreased p16 expression correlates with promoter methylation and poor prognosis. J Pathol 201: 487-495.

114. Ottaiano A, De Chiara A, Perrone F, Botti G, Fazioli F, et al. (2004) Prognostic value of CD40 in adult soft tissue sarcomas. Clin Cancer Res 10: 2824-2831.

115. de Silva MV, McMahon AD, Reid R (2004) Prognostic factors associated with local recurrence, metastases, and tumor-related death in patients with synovial sarcoma. Am J ClinOncol 27: 113-121.

116. Ahlén J, Wejde J, Brosjö O, von Rosen A, Weng WH, et al. (2005) Insulin-like growth factor type 1 receptor expression correlates to good prognosis in highly malignant soft tissue sarcoma. Clin Cancer Res 11: 206-216.

117. Benassi MS, Ponticelli F, Azzoni E, Gamberi G, Pazzaglia L, et al. (2007) Altered expression of urokinase-type plasminogen activator and plasminogen activator inhibitor in high-risk soft tissue sarcomas. HistolHistopathol 22: $1017-$ 1024.

118. Castilho-Fernandes A, de Almeida DC, Fontes AM, Melo FU, Picanço-Castro $V$, et al. (2011) Human hepatic stellate cell line (LX-2) exhibits characteristics of bone marrow-derived mesenchymal stem cells. ExpMolPathol 91: 664-672.

119. Melgar-Lesmes P, Pauta M, Reichenbach V, Casals G, Ros J, et al. (2011) Hypoxia and proinflammatory factors upregulateapelin receptor expression in human stellate cells and hepatocytes. Gut 60: 1404-1411.

120. Pfeffer U, Ferrari N, Morini M, Benelli R, Noonan DM, et al. (2003) Antiangiogenic activity of chemopreventive drugs. Int J Biol Markers 18: 70-74

121. Albini A, Tosetti F, Li VW, Noonan DM, Li WW (2012) Cancer prevention by targeting angiogenesis. Nat Rev ClinOncol 9: 498-509.

122. Campoli M, Ferris R, Ferrone S, Wang X (2010) Immunotherapy of malignant disease with tumor antigen-specific monoclonal antibodies. Clin Cancer Res 16: 11-20.

123. Rivera Z, Ferrone S, Wang X, Jube S, Yang H, et al. (2012) CSPG4 as a targe of antibody-based immunotherapy for malignant mesothelioma. Clin Cancer Res 18: 5352-5363.

124. Burrows FJ, Thorpe PE (1993) Eradication of large solid tumors in mice with an immunotoxin directed against tumor vasculature. ProcNatlAcadSci U S A 90: 8996-9000.

125. Folkman J (1995) Angiogenesis in cancer, vascular, rheumatoid and othe disease. Nat Med 1: 27-31.

126. Kerbel RS (1997) A cancer therapy resistant to resistance. Nature 390: 335336.

127. Kerbel RS (1991) Inhibition of tumor angiogenesis as a strategy to circumvent acquired resistance to anti-cancer therapeutic agents. Bioessays 13: 31-36.

128. Boehm T, Folkman J, Browder T, O'Reilly MS (1997) Antiangiogenic therapy of experimental cancer does not induce acquired drug resistance. Nature 390 404-407.

129. Smith MR (2003) Rituximab (monoclonal anti-CD20 antibody): mechanisms of action and resistance. Oncogene 22: 7359-7368.

130. Lin CC, Shen YC, Chuang CK, Liao SK (2001) Analysis of a murine antiganglioside GD2 monoclonal antibody expressing both $\operatorname{lgG} 2 a$ and $\operatorname{lgG} 3$ sotypes: monoclonality, apoptosis triggering, and activation of cellular cytotoxicity on human melanoma cells. AdvExp Med Biol 491: 419-429. 
Citation: Zhang H, Bie P, Leida Z, Xia Z, Bai L (2014) NG2/CSPG4 Proteoglycan as a Novel Prognostic Indicator and Therapeutic Target in Malignant Cancer. J Stem Cell Res Ther 4: 171. doi:10.4172/2157-7633.1000171

131. Baselga J, Albanell J (2001) Mechanism of action of anti-HER2 monoclonal antibodies. Ann Oncol 12: S35-41.

132. Epenetos AA, Snook D, Durbin H, Johnson PM, Taylor-Papadimitriou J (1986) Limitations of radiolabeled monoclonal antibodies for localization of human neoplasms. Cancer Res 46: 3183-3191.

133. Neuwelt EA, Specht HD, Barnett PA, Dahlborg SA, Miley A, et al. (1987) Increased delivery of tumor-specific monoclonal antibodies to brain after osmotic blood-brain barrier modification in patients with melanoma metastatic to the central nervous system. Neurosurgery 20: 885-895.

134.Jain RK, Baxter LT (1988) Mechanisms of heterogeneous distribution of monoclonal antibodies and other macromolecules in tumors: significance of elevated interstitial pressure. Cancer Res 48: 7022-7032.

135. Goodson RJ, Doyle MV, Kaufman SE, Rosenberg S (1994) High-affinity urokinase receptor antagonists identified with bacteriophage peptide display. ProcNatlAcadSci U S A 91: 7129-7133.
136. Burg MA, Pasqualini R, Arap W, Ruoslahti E, Stallcup WB (1999) NG2 proteoglycan-binding peptides target tumor neovasculature. Cancer Res 59: 2869-2874.

137. Murray JL, Gillogly M, Kawano K, Efferson CL, Lee JE, et al. (2004) Fine specificity of high molecular weight-melanoma-associated antigen-specific cytotoxic $\mathrm{T}$ lymphocytes elicited by anti-idiotypic monoclonal antibodies in patients with melanoma. Cancer Res 64: 5481-5488.

138. Kelly-Goss MR, Sweat RS, Stapor PC, Peirce SM, Murfee WL (2013) Targeting Pericytes for Angiogenic Therapies. Microcirculation.

139. Hannon GJ (2002) RNA interference. Nature 418: 244-251.

140. Jain RK (1997) Delivery of molecular and cellular medicine to solid tumors. Adv Drug Deliv Rev 26: 71-90.

141.Xu Z, Wei B, Ruan J, Zhu M, Hu Q, et al. (2011) Re: Cheng: shRNA targeting PLC inhibits bladder cancer cell growth in vitro and in vivo (Urology 2011;78: 474e.7-474e.11). Urology 78: 1446-1447. 